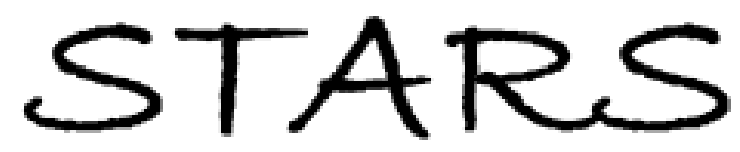

University of Central Florida

STARS

$1-1-1999$

\title{
Studies on passivation behavior of tungsten in application to chemical mechanical polishing
}

D. Tamboli

University of Central Florida

S. Seal

University of Central Florida

V. Desai

University of Central Florida

A. Maury

Find similar works at: https://stars.library.ucf.edu/facultybib1990

University of Central Florida Libraries http://library.ucf.edu

This Article; Proceedings Paper is brought to you for free and open access by the Faculty Bibliography at STARS. It has been accepted for inclusion in Faculty Bibliography 1990s by an authorized administrator of STARS. For more information, please contact STARS@ucf.edu.

\section{Recommended Citation}

Tamboli, D.; Seal, S.; Desai, V.; and Maury, A., "Studies on passivation behavior of tungsten in application to chemical mechanical polishing" (1999). Faculty Bibliography 1990s. 2866.

https://stars.library.ucf.edu/facultybib1990/2866

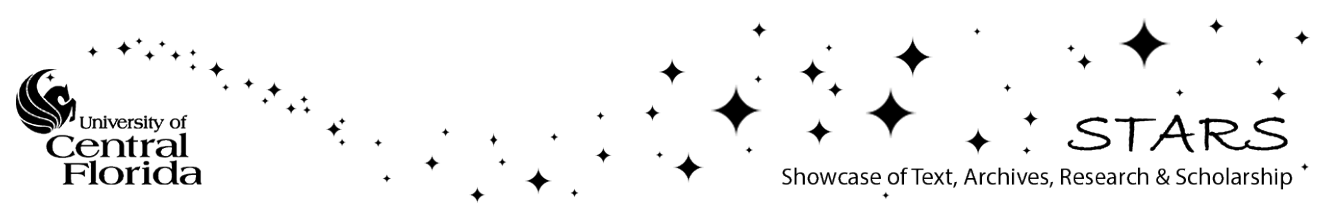




\section{Studies on passivation behavior of tungsten in application to chemical mechanical polishing}

D. Tamboli, S. Seal, V. Desai, and A. Maury

Citation: Journal of Vacuum Science \& Technology A 17, 1168 (1999); doi: 10.1116/1.581790

View online: https://doi.org/10.1116/1.581790

View Table of Contents: https://avs.scitation.org/toc/jva/17/4

Published by the American Vacuum Society

\section{ARTICLES YOU MAY BE INTERESTED IN}

Minimization of chemical-mechanical planarization (CMP) defects and post-CMP cleaning Journal of Vacuum Science \& Technology B: Microelectronics and Nanometer Structures Processing, Measurement, and Phenomena 17, 2248 (1999); https://doi.org/10.1116/1.590901

Surface chemistry of atomic layer deposition: A case study for the trimethylaluminum/water process Journal of Applied Physics 97, 121301 (2005); https://doi.org/10.1063/1.1940727

Tungsten etching mechanisms in $\mathrm{CF}_{4} / \mathrm{O}_{2}$ reactive ion etching plasmas

Journal of Applied Physics 66, 5034 (1989); https://doi.org/10.1063/1.343776

Study of tungsten oxidation in $\mathrm{O}_{2} / \mathrm{H}_{2} / \mathrm{N}_{2}$ downstream plasma Journal of Vacuum Science \& Technology A 26, 360 (2008); https://doi.org/10.1116/1.2897316

Effects of various oxidizers on chemical mechanical polishing performance of nickel for microelectromechanical system applications

Journal of Vacuum Science \& Technology A 24, 1297 (2006); https://doi.org/10.1116/1.2194926

Electrochemical behavior of copper chemical mechanical polishing in $\mathrm{KIO}_{3}$ slurry Journal of Vacuum Science \& Technology B: Microelectronics and Nanometer Structures Processing, Measurement, and Phenomena 20, 608 (2002); https://doi.org/10.1116/1.1458956

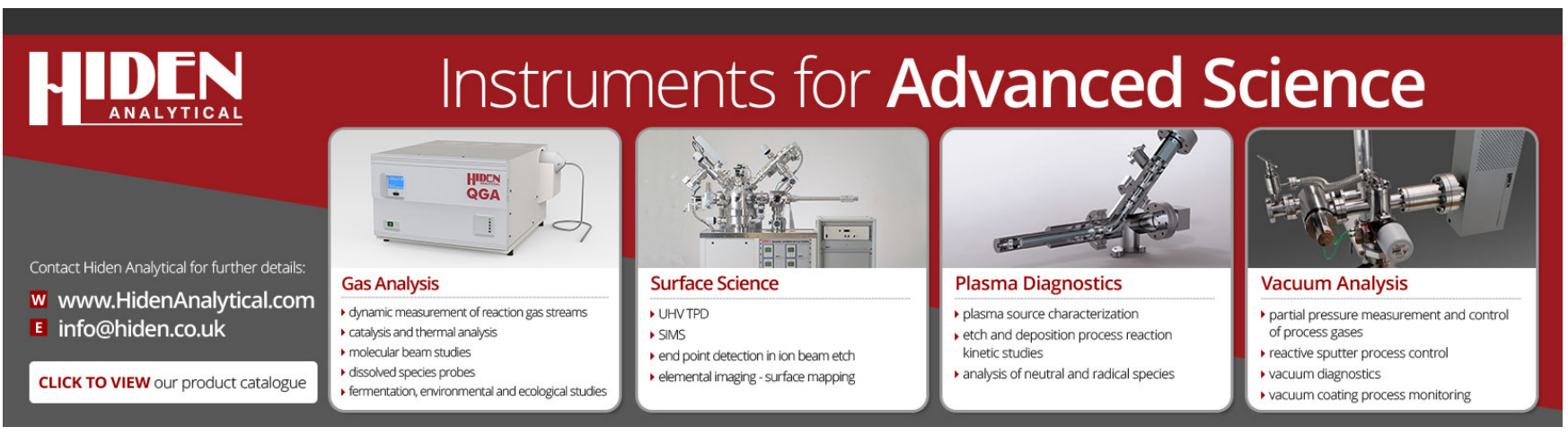




\title{
Studies on passivation behavior of tungsten in application to chemical mechanical polishing
}

\author{
D. Tamboli, ${ }^{\text {a) }}$ S. Seal, ${ }^{\text {b) }}$ and V. Desai \\ Advanced Materials Processing and Analysis Center (AMPAC), Mechanical, Materials and Aerospace \\ Engineering (MMAE), University of Central Florida, Orlando, Florida 32816 \\ A. Maury \\ Bell Labs-Lucent Technologies, Orlando, Florida 32819
}

(Received 2 November 1998; accepted 8 February 1999)

Chemical mechanical polishing (CMP) is considered to be the enabling technology for meeting the planarization requirements in $<0.35 \mu \mathrm{m}$ feature sized multilevel semiconductor device fabrication. CMP of tungsten is done in order to planarize and remove excess tungsten in the process to form inter-level contacts. Considerable importance is given to the role played by the passive oxide film formation on the surface during tungsten CMP. In this study, x-ray photoelectron spectroscopy (XPS) is used to understand the oxide growth mechanism in tungsten. Tungsten wafers are polarized to different anodic potentials in static $p \mathrm{H} 4$ solutions of $\mathrm{KIO} 3$ and $\mathrm{H}_{2} \mathrm{O}_{2}$, two commonly used oxidizers in CMP. XPS measurements are employed to probe the chemical and stoichiometric changes in the surface oxide films treated under these conditions. These results are then compared with the electrochemical polarization results. () 1999 American Vacuum Society.

[S0734-2101(99)08904-6]

\section{INTRODUCTION}

Tungsten is a widely used material in semiconductor industry for contact/via fill applications. ${ }^{1}$ Superior electromigration performance and the ability to form conformal coatings with excellent step coverage using low pressure chemical vapor deposition (LPCVD) process are the two main reasons for its use in these applications. The processing steps include deposition of blanket tungsten over a patterned wafer and subsequent removal of excess tungsten by chemical mechanical polishing (CMP) process. CMP not only removes the excess metal, but it also provides global planarity essential for below $0.35 \mu \mathrm{m}$ lithography in multilevel device fabrication. ${ }^{2}$

Kauffman et $a l .{ }^{3}$ have described the mechanism to explain excellent planarity and high removal rates in tungsten CMP on the basis of continuous cycles of passivation $\left(\mathrm{WO}_{3}\right.$ formation), abrasion of the oxide film, and ionic dissolution from exposed metal. Some literature studies have indeed shown that the corrosion current measured during polishing is directly proportional to the actual polishing rates. ${ }^{4,5}$ However, Kneer et al. ${ }^{6}$ have questioned the adequacy of this model by indicating that the tungsten dissolution rates as measured by in situ electrochemical current measurement constitute only a small fraction of tungsten removed in CMP. Based on atomic force microscopic study of polished wafers, they have suggested that corrosion assisted fracture may also be an important material removal mechanism in tungsten CMP. ${ }^{6}$ Another intriguing fact is that commercial slurries do not show any significant dependence of the CMP removal rates on the type of oxidizer used [such as $\left.\mathrm{H}_{2} \mathrm{O}_{2}, \mathrm{KIO}_{3}, \mathrm{~K} 3 \mathrm{Fe}(\mathrm{CN})_{6}, \mathrm{Fe}\left(\mathrm{NO}_{3}\right)_{3}\right]$ despite having widely different electrochemical dissolution rates of tungsten in the respective oxidizer solutions. ${ }^{7}$ Understanding the role of oxi-

\footnotetext{
${ }^{a)}$ Electronic mail: dct17275@pegasus.cc.ucf.edu

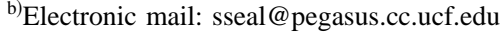

dizers in oxide formation and material removal by ionic dissolution is an important aspect in formulation of a CMP mechanism.

Tungsten is known to form a wide a range of oxides. Its most stable oxide is $\mathrm{WO}_{3}$. It is a wide band gap $(3.3 \mathrm{eV})$ insulating oxide. The other common oxide for tungsten is $\mathrm{WO}_{2} . \mathrm{WO}_{2}$ is a metallic conductor and is not considered a protective oxide. At $p \mathrm{H}$ values typical for CMP slurries, $\mathrm{WO}_{2}$ is believed to be present as a subsurface oxide below the outer $\mathrm{WO}_{3}$ layer. ${ }^{8}$ There is also a wide range of other nonstoichiometric oxides formed on tungsten. ${ }^{9,10}$ These oxides, however, are mostly reported for thermal oxidation of $\mathrm{W}$ or reduction treatments of $\mathrm{WO}_{3}$.

Very few detailed surface analytical studies are reported on characterization of the electrochemically formed passive oxide films on tungsten surface. ${ }^{8}$ In this study, the effects of $\mathrm{KIO}_{3}$ and $\mathrm{H}_{2} \mathrm{O}_{2}$, two commonly used oxidizers in tungsten CMP slurries on passivation and dissolution characteristics of tungsten are evaluated using $\mathrm{x}$-ray photoelectron spectroscopy (XPS) or electron spectroscopy for chemical analysis (ESCA) and electrochemical polarization techniques. The advantage of XPS is in its capability to detect small chemical shifts in the core level electron binding energy. ${ }^{11}$ This enables detection of tungsten in various chemical states and is valuable in the analysis of passive oxide films under the action of various oxidizers.

\section{EXPERIMENT}

The electrochemical and surface analytical studies were performed on $1.5 \times 1.5 \mathrm{~cm}$ pieces cut from a 8 in. diameter silicon wafer coated with $4000 \AA$ thick LPCVD tungsten layer. Sample preparation involved immersing the wafer in $45 \% \mathrm{KOH}$ solution for $5 \mathrm{~min}$ to remove the native tungsten oxides from the surface. The samples were then exposed to the oxidizer solutions in a K0235 model electrochemical flat cell. All the chemicals used in this study are of reagent 


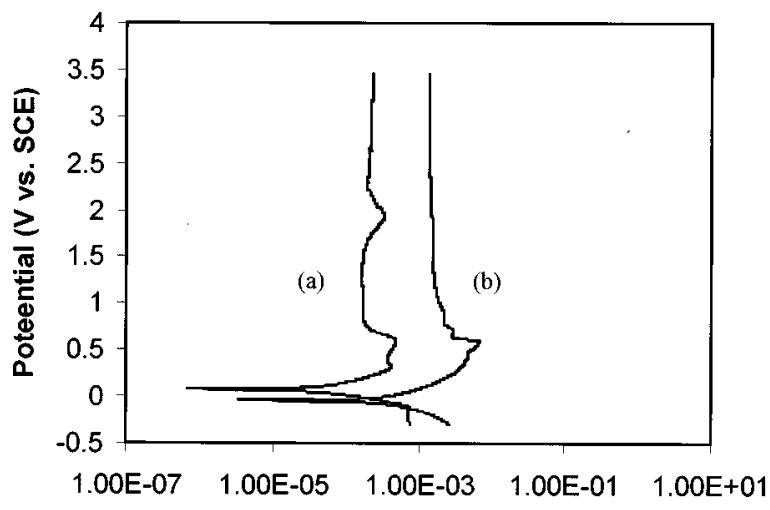

\section{Current density $\left(\mathbf{A} \mathbf{c m}^{\wedge} \mathbf{2}\right)$}

FIG. 1. Potentiodynamic polarization scans on tungsten wafer exposed to (a) $3.8 \% \mathrm{KIO}_{3}$ and (b) $5-\mathrm{vol} \% \mathrm{H}_{2} \mathrm{O}_{2}$ solution at $p \mathrm{H} 4$.

grade, purchased from Fisher Scientific. The $p \mathrm{H}$ of the solutions used in these experiments was maintained at 4 using a Fisher brand potassium bipthalate buffer solution. The studies were carried out on $3.8 \%$ by weight $\mathrm{KIO}_{3}$ solution and 5-vol $\% \mathrm{H}_{2} \mathrm{O}_{2}$ solution.

To evaluate the effect of oxidizers on electrochemical behavior of tungsten, two types of measurements were performed; (1) potentiodynamic polarization and (2) linear polarization. The samples were electrochemically polarized using EG\&G M273 potentiostat. In potentiodynamic polarization measurements, the sample is polarized from -0.25 to $3.5 \mathrm{~V}$ at a scan rate of $10 \mathrm{mV} / \mathrm{s}$. For linear polarization resistance measurement, the sample is polarized in the range of $20 \mathrm{mV}$ with respect to open circuit potential in both cathodic and anodic direction.

For XPS studies, the oxides were grown on the sample electrochemically by polarizing and holding the sample at selected test potentials $[0.5,1.8$, and $3 \mathrm{~V}$ with respect to (w.r.t.) standard calomel electrode (SCE)] for $1 \mathrm{~min}$. The samples were then transferred in an inert argon atmosphere to the XPS analysis chamber. XPS was performed using a PHI 5400 ESCA system. Nonmonochromatic Al $K \alpha$ x-ray source $(h \nu=1486.6 \mathrm{eV})$ at a power of $350 \mathrm{~W}$ was used for the analysis. The spectrometer was calibrated using $\mathrm{Au} 4 \mathrm{f}$ $7 / 2$ peak at $84 \pm 0.1 \mathrm{eV}$ (full width at half maximum of 0.8 $\mathrm{eV})$.

Spectral deconvolution was performed by first removing Shirley background ${ }^{12}$ by minimizing chi-squared using standard peak-fit software. The second and fourth derivatives of the spectrum were then inspected to locate position of various peaks. The core level peaks were then successfully fitted with component peaks with a Gaussian-Lorentzian distribution. Binding energy reference has been made with respect to $\mathrm{C}(1 s)$ peak at $284.6 \mathrm{eV} .^{13}$

\section{RESULTS}

\section{A. Electrochemical studies}

A marked difference is observed in the electrochemical behavior of tungsten in $\mathrm{KIO}_{3}$ and $\mathrm{H}_{2} \mathrm{O}_{2}$ solution. The corro-

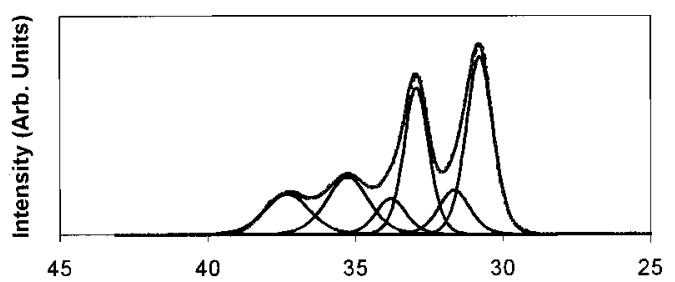

(a)

Binding Energy (eV)
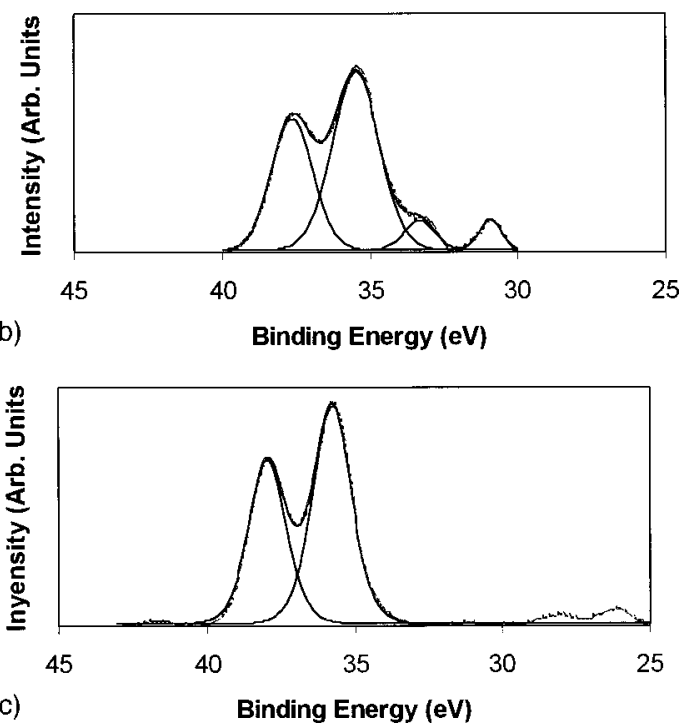

FIG. 2. XPS W $(4 f)$ spectra in sample oxidized in $3.8 \% \mathrm{KIO}_{3}$ solution at $p \mathrm{H}$ 4 at different applied potentials (a) 0.5 , (b) 1.8 , and (c) $3 \mathrm{~V}$ w.r.t. SCE. The dotted line is the observed spectrum after background subtraction. The solid line represents the composite spectrum obtained by addition of individual deconvoluted peaks shown in the figure.

sion potential $\left(E_{\text {corr }}\right)$ measured using $\mathrm{SCE}$ in $\mathrm{KIO}_{3}$ solution $(74 \mathrm{mV})$ is considerably more anodic than that measured in $\mathrm{H}_{2} \mathrm{O}_{2}$ solution $(-51 \mathrm{mV})$. The linear polarization measurements revealed a very low linear polarization resistance (196 $\Omega / \mathrm{cm}^{2}$ ) in $\mathrm{H}_{2} \mathrm{O}_{2}$ solution compared to that in $\mathrm{KIO}_{3}$ solution $\left(1830 \Omega / \mathrm{cm}^{2}\right)$, indicating high dissolution rates in $\mathrm{H}_{2} \mathrm{O}_{2}$ solution. Figure 1 shows the potentiodynamic polarization scans performed on $\mathrm{KOH}$ treated tungsten samples in 5-vol\% $\mathrm{H}_{2} \mathrm{O}_{2}$ and $3.8 \% \mathrm{KIO}_{3}$ solution. It is evident from these polarization curves that tungsten shows excellent passivation behavior in $3.8 \% \mathrm{KIO}_{3}$ solution. It also appears to show a passivation behavior in $\mathrm{H}_{2} \mathrm{O}_{2}$ solution also. However, the current density in this passivation regime is almost one order of magnitude higher than in $\mathrm{KIO}_{3}$ solution.

\section{B. XPS Results}

Figures 2 and 3 show the tungsten W $(4 f)$ spectra obtained on electrochemically oxidized tungsten in $\mathrm{KIO}_{3}$ and $\mathrm{H}_{2} \mathrm{O}_{2}$ solutions for $1 \mathrm{~min}$ at three potentials $0.5,1.8$, and $3 \mathrm{~V}$ (w.r.t. SCE) respectively. Figures 4 and 5 are the corresponding oxygen $\mathrm{O}(1 s)$ spectra for these oxidized samples. The binding energies of the peaks are tabulated in Table I.

The key features of the XPS analysis of tungsten specimens under selected oxidizing environments are the following.

(a) Deconvoluted XPS W $(4 f)$ spectra for samples oxidized at $0.5 \mathrm{~V}$ in $\mathrm{KIO}_{3}$ solution indicate the presence of a 


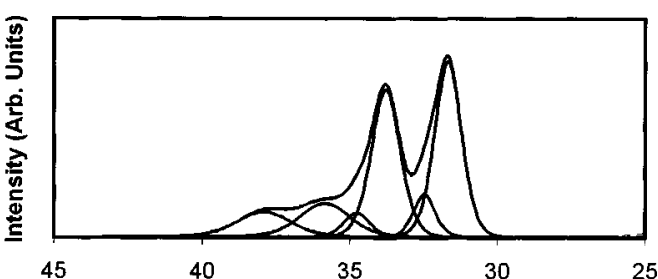

(a) Binding Energy (eV)

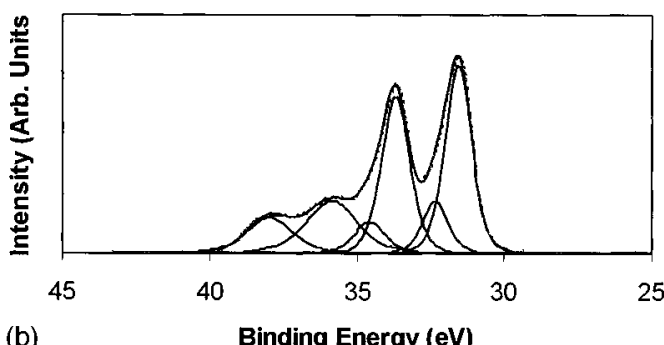

(b)

Binding Energy (eV)

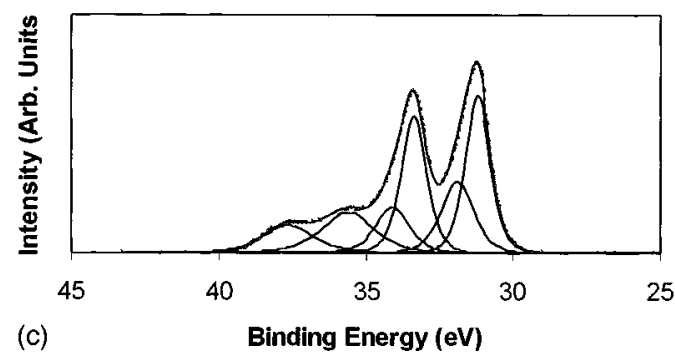

FIG. 3. XPS W $(4 f)$ spectra on samples oxidized in 5-vol $\% \mathrm{H}_{2} \mathrm{O}_{2}$ solution at $p \mathrm{H} 4$ at different applied potentials (a) 0.5, (b) 1.8, and (c) $3 \mathrm{~V}$ w.r.t. SCE. The dotted line is the observed spectrum after background subtraction. The solid line represents the composite spectrum obtained by addition of individual deconvoluted peaks shown in the figure.

tungsten spin orbit doublet at approximately 30.8 and $33 \mathrm{eV}$ (Fig. 2). No $\mathrm{WO}_{2}$ peak is seen in this case. Interestingly, for the $\mathrm{H}_{2} \mathrm{O}_{2}$ oxidized sample, the tungsten metallic spin orbit doublet peak is shifted to 31.6 and $33.8 \mathrm{eV}$ (Fig. 3). However, the $\mathrm{W}(4 f)$ binding energies of these spin orbit doublets $\left(\mathrm{W}^{0}\right)$ decreases at higher applied potentials in $\mathrm{H}_{2} \mathrm{O}_{2}$ solution.

(b) For samples oxidized in $\mathrm{KIO}_{3}$ solution, there is a systematic growth of $\mathrm{W}(4 f)$ peaks close to 35.5 and $37.7 \mathrm{eV}$ at the expense of metallic tungsten peaks at 30.9 and $33.1 \mathrm{eV}$, with increase in applied potential. The peaks at 35.5 and 37.7 $\mathrm{eV}( \pm 0.1 \mathrm{eV})$ are generally attributed to tungsten oxidized to its hexa-valent state $\left(\mathrm{WO}_{3}\right)$. For samples oxidized in $\mathrm{H}_{2} \mathrm{O}_{2}$, the transformation of metallic tungsten to its oxides is much smaller than it is for tungsten oxidized in $\mathrm{KIO}_{3}$ solution.

(c) The oxygen $1 \mathrm{~s}$ peak in tungsten oxidized in $\mathrm{KIO}_{3}$ is deconvoluted into two major oxygen peaks, one at binding energy $530.3-530.6 \mathrm{eV}$ range and the other at approximately $532 \mathrm{eV}$ (Fig. 4). A relatively insignificant peak at a binding energy close to $534 \mathrm{eV}$ is also observed. At higher applied potentials, a significant growth in the $532 \mathrm{eV}$ peak intensity is observed. The peak intensity at $530.3 \mathrm{eV}$ on the other hand decreases at higher applied potential. Samples oxidized in $\mathrm{H}_{2} \mathrm{O}_{2}$ solution also show two major oxygen peaks (Fig. 5). However, the intensities of the oxygen peaks at $532 \mathrm{eV}$ are much lower than those of the corresponding peaks oxidized in $\mathrm{KIO}_{3}$ solution. Additionally, there is a pronounced oxygen
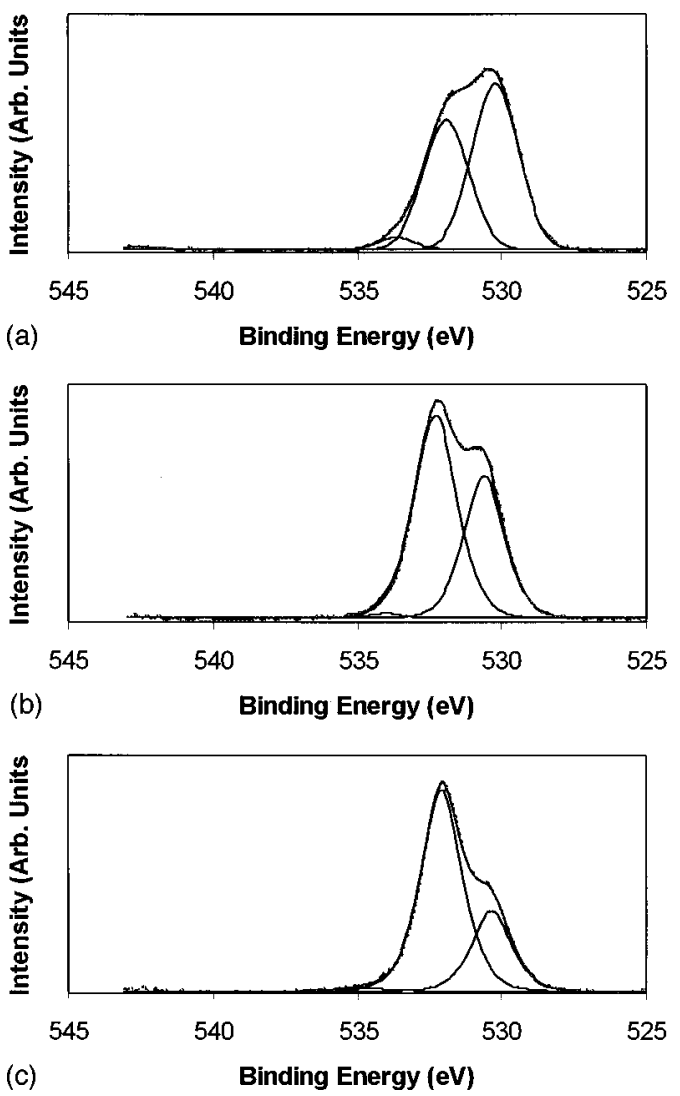

FIG. 4. XPS O $(1 s)$ spectra in sample oxidized in $3.8 \% \mathrm{KIO}_{3}$ solution at $p \mathrm{H}$ 4 at different applied potentials (a) 0.5 , (b) 1.8 , and (c) $3 \mathrm{~V}$ w.r.t. SCE. The dotted line is the observed spectrum after background subtraction. The solid line represents the composite spectrum obtained by addition of individual deconvoluted peaks shown in the figure.

peak at binding energy $533.3 \mathrm{eV}$ for these $\mathrm{H}_{2} \mathrm{O}_{2}$ oxidized samples.

\section{XPS Stoichiometry Calculations}

The stoichiometric calculations are based on integrated intensities measured for each deconvoluted peak. Average stoichiometry of oxides is calculated by summing $4 f_{7 / 2}$ tungsten peaks in all oxide forms. For oxygen, the integrated intensity under only the $530.3-530.6 \mathrm{eV}$ peak is used for calculations. The relative surface atomic concentration is calculated using the equation: ${ }^{11}$

$$
N_{\mathrm{O}} / N_{\mathrm{W}}=\left(I_{\mathrm{O}} / \sigma_{\mathrm{O}}\right) /\left(I_{\mathrm{W}} / \sigma_{\mathrm{W}}\right) \text {, }
$$

where $I_{\mathrm{O}}$ and $I_{\mathrm{W}}$ are the integrated intensities under oxygen and tungsten peaks in oxide form. $\sigma_{\mathrm{O}}$ and $\sigma_{\mathrm{W}}$ are the atomic sensitivity factors of $\mathrm{O} 1 s$ and $\mathrm{W} 4 f_{7 / 2}$ peaks, respectively. Area sensitivity factors used in these stoichiometry calculations are adapted from Briggs and Seah. ${ }^{14}$

The calculated values of stoichiometry are shown in Fig. 5 as a function of applied anodic potential in $\mathrm{H}_{2} \mathrm{O}_{2}$ and $\mathrm{KIO}_{3}$ solutions. It is apparent from the figure that the oxygen to tungsten ratios in the samples oxidized at higher potentials approaches to about 3.1 at high potentials for samples oxidized in $\mathrm{KIO}_{3}$ solution. On the other hand, with an increase 


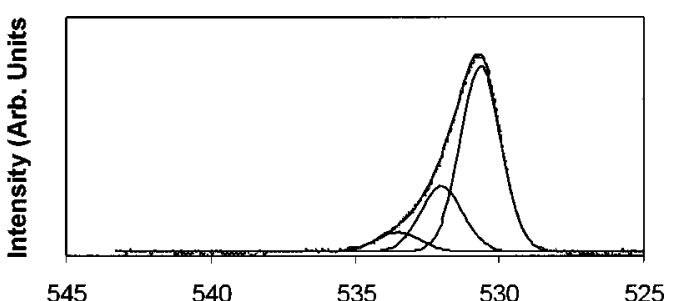

(a) Binding Energy (eV)

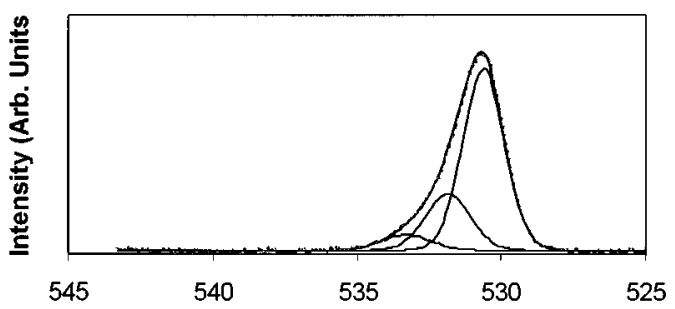

(b) Binding Energy (eV)

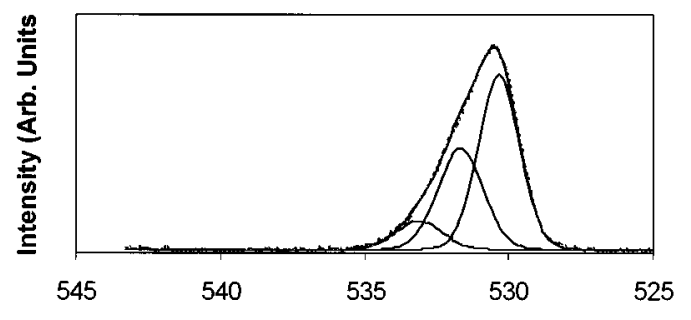

(c)

Binding Energy (eV)

FIG. 5. XPS O $(1 s)$ spectra on samples oxidized in 5-vol $\% \mathrm{H}_{2} \mathrm{O}_{2}$ solution at $p \mathrm{H} 4$ at different applied potentials (a) 0.5 , (b) 1.8 , and (c) $3 \mathrm{~V}$ w.r.t. SCE. The dotted line is the observed spectrum after background subtraction. The solid line represents the composite spectrum obtained by addition of individual deconvoluted peaks shown in the figure.

in applied potential to $3 \mathrm{~V}$ vs SCE, oxygen to tungsten ratio for the sample oxidized in $\mathrm{H}_{2} \mathrm{O}_{2}$ solution drops from about 2.5 to 1.6. This decrease is consistent with the increased intensity for an intermediate tungsten oxide peak at a low binding energy $(31.9 \mathrm{eV})$, which indicates presence of a lower tungsten valency in the oxide.

TABLE I. XPS W $(4 f)$ and $\mathrm{O}(1 s)$ core level binding energies (in $\mathrm{eV}$ : accuracy $\pm 0.1 \mathrm{eV}$ ) of various oxidizer treated tungsten wafer.

\begin{tabular}{|c|c|c|c|c|}
\hline \multirow[b]{2}{*}{ Peak } & \multirow[b]{2}{*}{ Oxidizer } & \multicolumn{3}{|c|}{ Applied Potential } \\
\hline & & $0.5 \mathrm{~V}$ & $1.8 \mathrm{~V}$ & $3 \mathrm{~V}$ \\
\hline \multirow[t]{6}{*}{$\mathrm{W} 4 f_{7 / 2}(\mathrm{eV})$} & \multirow[t]{3}{*}{$\mathrm{KIO}_{3}$} & $30.8 /$ & 30.9 & $\ldots$ \\
\hline & & 31.6 & $\ldots$ & $\ldots$ \\
\hline & & 35.2 & 35.4 & 35.8 \\
\hline & \multirow[t]{3}{*}{$\mathrm{H}_{2} \mathrm{O}_{2}$} & 31.7 & 31.5 & 31.2 \\
\hline & & 32.5 & 32.3 & 31.9 \\
\hline & & 35.8 & 35.8 & 35.6 \\
\hline \multirow[t]{6}{*}{$\mathrm{O} 1 s(\mathrm{eV})$} & \multirow[t]{3}{*}{$\mathrm{KIO}_{3}$} & 530.3 & 530.6 & 530.3 \\
\hline & & 531.9 & 532.3 & 532.1 \\
\hline & & 533.8 & 534 & 533.9 \\
\hline & \multirow[t]{3}{*}{$\mathrm{H}_{2} \mathrm{O}_{2}$} & 530.6 & 530.6 & 530.3 \\
\hline & & 532 & 531.8 & 531.7 \\
\hline & & 533.5 & 533.3 & 533.1 \\
\hline
\end{tabular}

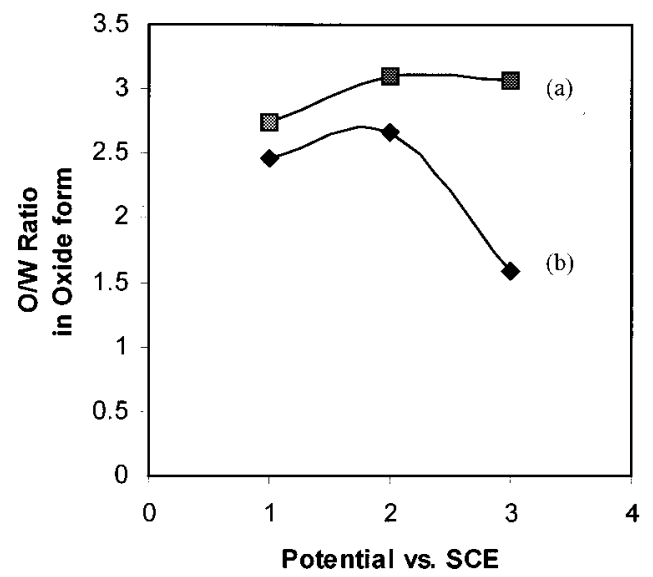

FIG. 6. Relative XPS O/W ratio in tungsten oxides formed at different potentials in (a) $3.8 \% \mathrm{KIO}_{3}$ and (b) 5 -vol $\% \mathrm{H}_{2} \mathrm{O}_{2}$ solutions at $p \mathrm{H} 4$.

Figure 6 shows the total oxygen to total tungsten ratio calculated. It shows a drastic increase in $\mathrm{O} / \mathrm{W}$ ratio with applied potential for $\mathrm{KIO}_{3}$ oxidized sample. This increase mostly results from a sharp rise in the intensity of $532 \mathrm{eV}$ oxygen peak with applied potential. For hydrogen peroxide, the increase in $532 \mathrm{eV}$ peak intensity is much smaller, resulting in a relatively insignificant change in $\mathrm{O} / \mathrm{W}$ ratio.

\section{DISCUSSION}

Understanding the structure of electrochemically formed thin passive oxide films on the metal surface is challenging. It is postulated that the structure of the passive film on the metal consists of two layers; (1) inner compact barrier film and (2) outer precipitated layer. The compact barrier film is considered noncrystalline and glassy in nature. The outer porous, precipitated layer results from cations emerging out of the barrier layer. ${ }^{15,16}$ This layer is considerably hydrated. The film contains three different bridges $-\mathrm{H}_{2} \mathrm{O}-\mathrm{M}-\mathrm{H}_{2} \mathrm{O}-$, $-\mathrm{HO}-\mathrm{M}-\mathrm{HO}-$ and $-\mathrm{O}-\mathrm{M}-\mathrm{O}$. During advanced stages of oxidation, the $-\mathrm{OH}$ type bonds are converted to $-\mathrm{O}-\mathrm{M}-\mathrm{O}-$ type bonds, resulting in improved protective properties of the oxides. $^{17}$

As discussed earlier, the oxygen spectra recorded on sample oxidized in $\mathrm{KIO}_{3}$ solution show three oxygen peaks at 530.3-530.6, 532, and $533 \mathrm{eV}$, respectively. The peak at binding energy 530.3-530.6 eV can be unambiguously attributed to solid $-\mathrm{M}-\mathrm{O}-$ type of bonding. ${ }^{17-24}$ The peak close to $532 \mathrm{eV}$ is generally attributed in the literature to $1 \mathrm{~s}$ peak corresponding to oxygen atom in hydroxyl groups bonded to the metal. ${ }^{17-24}$ However, direct attribution of 532 $\mathrm{eV}$ peak to oxygen in $\mathrm{M}-\mathrm{OH}$ type of bond is not possible in this study because of two reasons:

(1) There is no evidence of $\mathrm{W}-\mathrm{OH}$ - type of bonds in tungsten core level and valence band regions. The spectra obtained for sample oxidized at $3 \mathrm{~V}$ which shows the highest oxygen peak at $532 \mathrm{eV}$ show only $\mathrm{WO}_{3}$ peaks. There is no peak broadening to indicate the possibility of hidden hydroxide peaks in the $\mathrm{W}(4 f)$ region.

(2) The valence bands of oxides and hydroxides may show considerable differences. ${ }^{25}$ From the valence band 

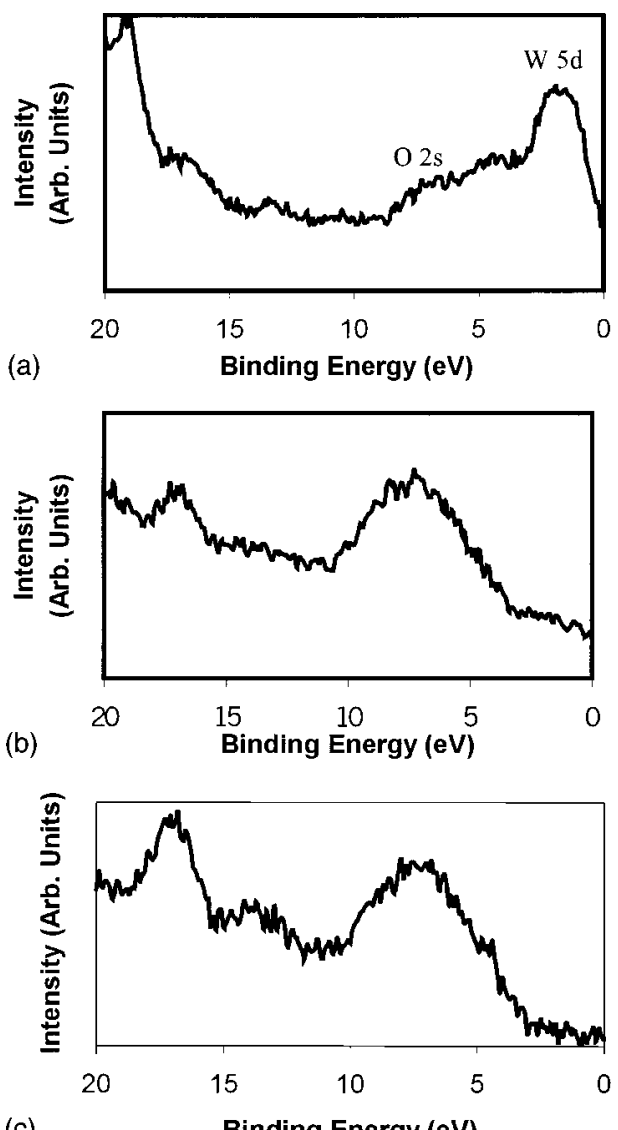

(c)

Binding Energy (eV)

FIG. 7. XPS valence band spectra on tungsten oxidized in $3.8 \% \mathrm{KIO}_{3} p \mathrm{H} 4$ solution at (a) $0.5 \mathrm{~V}$, (b) $1.8 \mathrm{~V}$, and (c) $3 \mathrm{~V}$ w.r.t. SCE.

spectra we observe the decreasing intensity of $\mathrm{W} 5 d$ density of states (owing to $\mathrm{W} \rightarrow \mathrm{WO}_{3}$ transformation) with increasing applied potentials in $\mathrm{KIO}_{3}$ solution. Apart from that no significant changes are observed in terms peak structure in the valence band region (Fig. 7).

Thus one can attribute this $532 \mathrm{eV}$ peak to be adsorbed $\mathrm{OH}$ on the $\mathrm{W}$ surface. The binding energy for the physisorbed water on gold surface is reported to be in the range of $533.5-534 \mathrm{eV}^{26}$ The lower $\mathrm{O}(1 s)$ binding energy values $(532.2 \mathrm{eV})$ observed in this case may indicate chemisorbed $\mathrm{OH}$ groups.

The increase in $532 \mathrm{eV}$ oxygen peak intensity with applied potential, is in contrast with several reports which show a decrease in intensity for that peak at higher applied potentials. ${ }^{17-20}$ However, these studies have been mainly reported on bi-valent or tri-valent metals. Molybdenum, which forms a quadravalent metal oxide on the other hand, appears to show an increase in $532 \mathrm{eV}$ peak intensity with applied potential. However, the increase is somewhat smaller than that observed for $530 \mathrm{eV}$ peak intensity. ${ }^{27}$ The differences in the dependence of $\mathrm{O} 1 \mathrm{~s}$ spectra on anodic potential for different oxides can be attributed to the differences in ionic transport properties of the oxides. Valency of cations in oxides plays a crucial role in determining ionic transport properties and the growth mechanism of the oxides. In hexavalent tungsten oxide, the cation vacancy generation is much

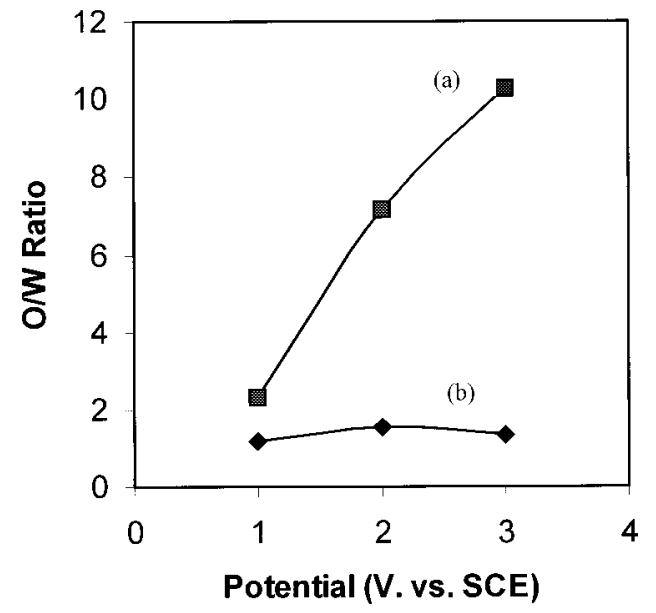

FIG. 8. Variation in ratio of total oxygen content to tungsten content with polarization potential in (a) $3.8 \% \mathrm{KIO}_{3}$ and (b) 5-vol $\% \mathrm{H}_{2} \mathrm{O}_{2}$ solution at pH 4 .

more difficult than in a bi- or tri-valent metal oxide. Tungsten oxides being anion conductor, oxidation would be expected to take place primarily at the oxide/metal interface and not at oxide/solution interface as is the case for bi- or tri-valent metals. The adsorbed $\mathrm{OH}$ ions on the surface may be the primary sources for oxygen and electrons in tungsten oxidation. At higher potentials the formation of $\mathrm{OH}$ ions is accelerated, to keep pace with the increased oxide growth rates and thus the observed increase in total oxygen to tungsten ratio as shown in Fig. 8. McDonald, Biaggio, and Song have modified the high field conduction theory of oxide growth using the vacancy transport mechanism. ${ }^{28}$ Based on this "point defect' model, they have developed diagnostic criterion for determining electrochemical oxide growth mechanisms. As it will be discussed elsewhere, ${ }^{29}$ a strong dependence of steady state current density on $p \mathrm{H}$ in $\mathrm{KIO}_{3}$ solutions was found. Based on diagnostic criterion developed by Macdonald, Biaggio, and Song, it can be confirmed that $\mathrm{WO}_{3}$ formed in $\mathrm{KIO}_{3}$ solutions is an anion conducting film.

Oxidizing action of $\mathrm{H}_{2} \mathrm{O}_{2}$ is very different from that of $\mathrm{KIO}_{3}$. As seen in Fig. 1, there is an appearance of a "passivation regime" during anodic polarization in $\mathrm{H}_{2} \mathrm{O}_{2}$ solution. Some earlier publications attributed this high current densities in the passive region to porosity and defects in the oxide films. ${ }^{8,30}$ No surface characterization data, however, was provided to support this hypothesis. Our XPS data do not show any growth in $\mathrm{WO}_{3}$ peak intensity expected with the passivation behavior. The appearance of the passivation regime can therefore be attributed to the current limited by mass transfer process. $\mathrm{H}_{2} \mathrm{O}_{2}$ is known to form complex peroxopolytungstic acids $\left(12 \mathrm{WO}_{3} \cdot 7 \mathrm{H}_{2} \mathrm{O}_{2} \cdot m \mathrm{H}_{2} \mathrm{O}\right)$ through the reaction with tungsten. ${ }^{31}$ It is possible that this reaction is taking place through the dissolution of tungsten oxides. To confirm this hypothesis, an experiment was carried out in which $\mathrm{WO}_{3}$ was first formed on the tungsten electrode by anodic polarization at $3 \mathrm{~V}$ in $p \mathrm{H} 4$ buffer solution for $10 \mathrm{~min}$. The polarization resistance measured after the anodic oxide formation in that solution was $71 \mathrm{k} \Omega / \mathrm{cm}^{2}$. However, after 1 min of 
immersion in $\mathrm{H}_{2} \mathrm{O}_{2}$ solution, the polarization resistance dropped to $182 \Omega / \mathrm{cm}^{2}$. This rapid drop in polarization resistance is an indicative of the fast dissolution of $\mathrm{WO}_{3}$ in $\mathrm{H}_{2} \mathrm{O}_{2}$ solution. The oxygen $1 s$ peak of sample oxidized in $\mathrm{H}_{2} \mathrm{O}_{2}$ solution show a pronounced peak at $533.3 \mathrm{eV}$. Like the $\mathrm{W} 4 f$ peak in hexa-valent oxidized state, this oxygen peak intensity does not show any applied potential dependence. This peak is likely to be associated with the $\mathrm{OH}$ groups bonded to $\mathrm{WO}_{3}$ to form a complex.

The other important feature of the results is the observed tungsten peaks at approximately $31.5 \mathrm{eV}$ and the dependence of this peak position with the applied potential particularly for samples oxidized in $\mathrm{H}_{2} \mathrm{O}_{2}$. A binding energy of $31.5 \mathrm{eV}$ is too low to be attributed to tungsten $[\mathrm{W}(4 f 7 / 2)]$ in $\mathrm{WO}_{2-\mathrm{x}}$ or even WO. The only plausible explanation for these peaks can be shifted in $\mathrm{W}^{\mathrm{O}}$ peak resulting from increased charge transfer between $\mathrm{W}$ and $\mathrm{H}_{2} \mathrm{O}_{2} \cdot \mathrm{H}_{2} \mathrm{O}_{2}$ is a strong oxidizer and hence, a strong electron acceptor. In the presence of $\mathrm{H}_{2} \mathrm{O}_{2}$, the $\mathrm{W}$ surface is more ionic in nature and hence, leads to an increase in the $\mathrm{W} 4 f$ core level binding energy. The increased ionic nature of the tungsten surface in $\mathrm{H}_{2} \mathrm{O}_{2}$ solution is also evident from more active corrosion potential and high dissolution rates measured in that solution. The decrease in W $4 f$ binding energies at higher applied potentials may be associated with increased transformation of metallic tungsten to its oxide forms (Fig. 3). At higher potentials, the formation of sub-stoichiometric $\mathrm{WO}_{2}$ appears to be prevalent as reflected in the lowering binding energies for the $\mathrm{WO}_{2}$ peaks. Similar behavior is observed for sample oxidized in $\mathrm{KIO}_{3}$, where a $31.7 \mathrm{eV}$ peak is observed instead of $32.5 \mathrm{eV} \mathrm{WO}$ peak.

\section{CONCLUSIONS}

In this study, the effect of $\mathrm{KIO}_{3}$ and $\mathrm{H}_{2} \mathrm{O}_{2}$, two commonly used oxidizers in tungsten CMP slurries, on passivation and dissolution characteristics of tungsten is evaluated using XPS and electrochemical polarization techniques. Significant differences in passive oxide growth processes for tungsten in $\mathrm{KIO}_{3}$ and $\mathrm{H}_{2} \mathrm{O}_{2}$ solutions are observed. Anodic oxidation of tungsten in $\mathrm{KIO}_{3}$ solution results in $\mathrm{WO}_{3}$ formation with a growth rate increasing with an increase in applied potential. A substantial increase in adsorbed $\mathrm{OH}$ groups is also observed at higher applied potential, which is in contrast with the published reports on oxidation of $\mathrm{Fe}, \mathrm{Ni}$, and their alloys. ${ }^{17-20}$ These differences can be explained on the basis of the "point defect" model for oxide growth. ${ }^{28}$ Because bi-valent anion vacancies are much easier to form than hexavalent tungsten cation vacancies, the mechanism of oxide growth is likely to be dominated by anion transport in the oxide. Consequently, an increase in adsorbed $\mathrm{OH}$ groups would be expected at higher polarization potentials to achieve higher initial oxide growth rates.

High current densities are observed in the passive region of tungsten oxidation during $\mathrm{H}_{2} \mathrm{O}_{2}$ oxidation. This behavior can be attributed to high oxide dissolution at oxide/solution interface to form a complex peroxo poly-tungstic acids. ${ }^{31}$
The appearance of the passivation regime can be attributed to current limited by mass transfer process during dissolution of oxides.

The differences in the nature of the tungsten-oxidizer interaction shown in this study has demonstrated the need for a further detailed study on surface chemistry modification in CMP process to explain material removal mechanism. Metallic tungsten is believed to dissolve as $\mathrm{WO}_{4}^{2-}$. This reaction is likely to proceed through formation of oxide. Based on the results of this study, we can speculate that there may be a significant inward oxygen migration. Detailed studies on the role of oxygen on electrochemical and mechanical removal of tungsten in CMP are currently underway.

${ }^{1}$ J. M. Steigerwald, S. P. Murarka, and R. J. Gutmann, Chemical Mechanical Planarization of Microelectronic Materials (Wiley, New York, 1997). ${ }^{2}$ M. Rutten, P. Feeny, R. Cheek, and W. Landers, Semicond. Int. (Sept. 1995), p. 123.

${ }^{3}$ F. B. Kaufman, D. B. Thompson, R. E. Broadie, M. A. Jaso, W. L. Gutherie, D. J. Pearson, and M. B. Small, J. Electrochem. Soc. 138, 3460 (1991).

${ }^{4}$ C. C. Streinz, D. Ligocki, T. Myres, V. Brusic, in Chemical Mechanical Planarization, edited by I. Ali and S. Raghavan, The Electrochemical Society Proceedings 96-22, 159 (1996) (The Electrochemical Society, New Jersey, 1996).

${ }^{5}$ J. Farkas, R. Caprio, R. Bajaj, C. Galanakis, R. Jairath, B. Jones, and S. Tzeng, in Advanced Metallization for ULSI Applications in 1994, edited by R. Blumenthal and G. Janssen (Materials Research Society, Pennsylvania, 1995).

${ }^{6}$ E. A. Kneer, C. Raghunath, V. Mathew, S. Raghavan, and J. S. Jeon, J. Electrochem. Soc. 144, 3041 (1997).

${ }^{7}$ D. Tamboli, S. Seal, and V. Desai (unpublished).

${ }^{8}$ E. A. Kneer, C. Raghunath, S. Raghavan, and J. S. Jeon, J. Electrochem. Soc. 143, 4095 (1996).

${ }^{9}$ B. De Angelis and M. Schiavello, J. Solid State Chem. 21, 67 (1977).

${ }^{10}$ R. Gehlig, E. Salje, A. Carley, and M. Roberts, J. Solid State Chem. 49, 318 (1983).

${ }^{11}$ T. L. Barr, Modern ESCA (CRC Press, Boca Raton, FL, 1994).

${ }^{12}$ D. H. Shirley, Phys. Rev. B 5, 4709 (1972).

${ }^{13}$ T. Barr, S. Seal, J. Vac. Sci. Technol. A 13, 1239 (1995).

${ }^{14}$ D. Briggs and M. P. Seah, Practical Surface Analysis (Wiley, New York, 1990).

${ }^{15}$ G. Okamoto, Corros. Sci. 13, 471 (1973).

${ }^{16} \mathrm{D}$. Macdonald and M. Urquidi-Macdonald, J. Electrochem. Soc. 137, 2395 (1990).

${ }^{17}$ M. Ben-Haim, U. Atzmony, and N. Shamir, Corrosion (Houston) 44, 461 (1998).

${ }^{18}$ H. Hoppe and H. Strehblow, Corros. Sci. 31, 167 (1990).

${ }^{19}$ I. Olefjord and L. Werglius, Corros. Sci. 31, 88 (1990).

${ }^{20}$ D. Shoesmith, S. Sunder, M. Bailey, G. Wallace, and F. Stanchell, J. Electrochem. Soc. 143, 153 (1983).

${ }^{21}$ K. Asami, K. Hashimoto, and S. Shimodaira, Corros. Sci. 16, 387 (1976).

${ }^{22}$ K. Asami, K. Hashimoto, and S. Shimodaira, Corros. Sci. 16, 35 (1976).

${ }^{23}$ K. Asami and K. Hashimoto, Corros. Sci. 17, 559 (1977).

${ }^{24}$ K. Asami, K. Hashimoto, and S. Shimodaira, Corros. Sci. 17, 713 (1977).

${ }^{25}$ I. Welsh and P. Sherwood, Phys. Rev. B 40, 6386 (1989).

${ }^{26}$ C. Brundle and M. Roberts, Proc. R. Soc. London, Ser. A 331, 383 (1972).

${ }^{27}$ M. Urgen, U. Stolz, and R. Kirchheim, Corros. Sci. 30, 377 (1990).

${ }^{28}$ D. Macdonald, S. Biaggio, and H. Song, J. Electrochem. Soc. 139, 170 (1992).

${ }^{29}$ D. Tamboli, S. Seal, and V. Desai (unpublished).

${ }^{30} \mathrm{~S}$. Basak, K. Misra, B. Whithers, and K. Rajeshwar, in Chemical Mechanical Planarization, edited by I. Ali and S. Raghavan, The Electrochemical Society Proceedings 96-22, 137 (1996) (The Electrochemical Society, New Jersey, 1996)

${ }^{31}$ T. Kudo, H. Okomoto, K. Matsumoto, and Y. Sasaki, Inorg. Chim. Acta 111, 27 (1986). 